\title{
Dipeptidyl peptidase 4 - an important digestive peptidase in Tenebrio molitor
} larvae

Valeriia F. Tereshchenkova ${ }^{a}$, Irina A. Goptar ${ }^{\mathrm{a}}$, Irina A. Kulemzina ${ }^{\mathrm{b}}$, Dmitry P. Zhuzhikov $^{\mathrm{c}}$, Marina V. Serebryakova ${ }^{\mathrm{d}}$, Mikhail A. Belozerskyd, Yakov E. Dunaevsky $^{\mathrm{d}}$, Brenda Oppert ${ }^{\mathrm{e} *}$, Irina Yu. Filippova ${ }^{\mathrm{a}}$ and Elena N. Elpidina ${ }^{\mathrm{d}}$

${ }^{a}$ Chemical Faculty, Lomonosov Moscow State University, Moscow 119991, Russia ${ }^{b}$ Faculty of Bioengineering and Bioinformatics, Lomonosov Moscow State University, Moscow 119991, Russia

'Biological Faculty, Lomonosov Moscow State University, Moscow 119991, Russia ${ }^{\mathrm{d} A . N}$. Belozersky Institute of Physico-Chemical Biology, Lomonosov Moscow State University, Moscow 119991, Russia

'USDA Agricultural Research Service, Center for Grain and Animal Health Research, 1515 College Ave., Manhattan, KS 66502, USA

*Corresponding author:

bso@ksu.edu

\begin{abstract}
Dipeptidyl peptidase 4 (DPP 4) is a proline specific serine peptidase that plays an important role in different regulatory processes in mammals. In this report, we isolated and characterized a unique secreted digestive DPP 4 from the anterior midgut of a stored product pest, Tenebrio molitor larvae (TmDPP 4), with a biological function different than that of the well-studied mammalian DPP 4. The sequence of the purified enzyme was confirmed by mass-spectrometry, and was identical to the translated RNA sequence found in a gut EST database. The purified peptidase was
\end{abstract}


characterized according to its localization in the midgut, and substrate specificity and inhibitor sensitivity were compared with those of human recombinant DPP 4 (rhDPP 4). The T. molitor enzyme was localized mainly in the anterior midgut of the larvae, and $81 \%$ of the activity was found in the fraction of soluble gut contents, while human DPP 4 is a membrane enzyme. TmDPP 4 was stable in the $\mathrm{pH}$ range 5.0-9.0, with an optimum activity at $\mathrm{pH} 7.9$, similar to human DPP 4. Only specific inhibitors of serine peptidases, diisopropyl fluorophosphate and phenylmethylsulfonyl fluoride, suppressed TmDPP 4 activity, and the specific dipeptidyl peptidase inhibitor vildagliptin was most potent. The highest rate of TmDPP 4 hydrolysis was found for the synthetic substrate Arg-Pro-pNA, while Ala-Pro-pNA was a better substrate for rhDPP 4. Related to its function in the insect midgut, TmDPP 4 efficiently hydrolyzed the wheat storage proteins gliadins, which are major dietary proteins of $T$. molitor.

\section{Keywords}

dipeptidyl peptidase 4; DPP 4; insect digestive peptidases; proline specific serine peptidase; yellow mealworm, Tenebrio molitor

\section{Abbreviations}

AM - anterior midgut

$\mathrm{PM}$ - posterior midgut

Abz- $O$-aminobenzoyl

AMC - 7-amino-4-methylcoumarin

$\mathrm{Bz}$ - benzoyl

DMF - dimethylformamide

Glp - pyroglutamyl

OU - optical units 
PAGE - polyacrylamide gel electrophoresis

pNA $-p$-nitroanilide

Suc - succinyl

TNBS - 2,4,6-trinitrobenzene sulfonic acid

$\mathrm{Z}$ - benzyloxycarbonyl

Peptidases:

AARE - acylaminoacyl peptidase

AP - aminopeptidase

APP - aminopeptidase P

DPP 4 - dipeptidyl peptidase 4

FAP - fibroblast activation protein

PEP - prolyl endopeptidase

POP - prolyl oligopeptidase

PRCP - prolyl carboxypeptidase

PSP - proline specific peptidases

rhDPP 4 - recombinant human dipeptidyl peptidase 4

TmDPP 4 - Tenebrio molitor dipeptidyl peptidase 4

Inhibitors:

DFP - diisopropyl fluorophosphate

diprotin A - Ile-Pro-Ile

diprotin B - Val-Pro-Leu

E-64 - trans-Epoxysuccinyl-L-leucylamido(4-guanidino)butane

EDTA - ethylenediaminetetraacetic acid

PMSF - phenylmethylsulfonyl fluoride

TLCK - $\mathrm{N}_{\alpha}$-Tosyl-L-lysine chloromethyl ketone hydrochloride 


\section{Introduction}

Dipeptidyl peptidase 4 (DPP 4, EC 3.4.14.5) belongs to a group of proline specific peptidases (PSP), which hydrolyze peptide bonds formed by proline. Proline is a unique imino acid among the 20 natural proteinogenic amino acids, and the bonds formed by proline are resistant to hydrolysis by most peptidases with broad substrate specificity. In biologically active peptides, proline performs a protective function, preventing peptides from degradation by nonspecific peptidases (Cunningham and O’Connor, 1997).

DPP 4 is the most well studied member of the PSP group. The enzyme belongs to the subfamily S9B of serine peptidases (Rawlings et al., 2014). DPP 4 cleaves dipeptides from the $\mathrm{N}$-terminus of a peptide chain of any length, and proline is the most preferred residue in the P1 position (David et al., 1993). DPP 4 has been found in mammals (Erickson et al., 1983), insects (Chihara et al., 2005), plants (Davy et al., 2000) and microorganisms (Gazi et al., 1995; Kabashima et al., 1995).

The most well studied human DPP 4, also found in other mammals, is present in two forms: a transmembrane glycoprotein, occurring on the surface of some types of cells, or as a soluble enzyme. The transmembrane form is present on the surface of T-cells (Tanaka et al., 1992), expressed specifically in lymphatic vessels but not in blood vessels, in tissues such as the skin, small intestine, esophagus, ovary, breast and prostate gland (Shin et al., 2008). The enzyme also was found on the surface of epithelial cells of kidney, liver, salivary glands (Fukasawa et al., 1981), and small intestine (Gorvel et al., 1991). A soluble form derived from the membrane form by proteolytic processing was found in human serum (Iwaki-Egawa et al., 1998; Durinx et al., 2000). The mammalian enzyme is reported to be a dimer, with subunit

molecular masses in the range 100-130 kDa (Cunningham and O'Connor, 1997). The $\mathrm{pH}$-optimum of the enzyme is in the range of 8 to 9 , and the isoelectric point (pI) is in the range of 3.0-5.0 (Yoshimoto et al., 1978). 
The activity of DPP 4 is suppressed by class-specific inhibitors of serine peptidases, such as diisopropyl fluorophosphate (DFP) and phenylmethylsulfonyl fluoride (PMSF). Inhibitors of other classes of peptidases have no effect on the activity of the enzyme (Kenny et al., 1976; Puschel et al., 1982). However, the activity of bacterial DPP 4 from the swine pathogen Streptococcus suis is inhibited by $\mathrm{Hg}^{2+}$ (Jobin et al., 2005), which suggests the presence of a Cys residue, important for catalysis. Specific inhibitors, such as diprotin A (Ile-Pro-Ile), diprotin B (Val-ProLeu) (Umezawa et al., 1984; Rahfeld et al., 1991; Ronai et al., 1999), Xaa-boroPro (Flentke et al., 1991) and a series of aminoacylpirrolidines (Sakashita et al., 2006), can reduce DPP 4 activity.

In this paper, we describe and fully characterize the first insect DPP 4 in larvae of the yellow mealworm, Tenebrio molitor (Coleoptera: Tenebrionidae), a stored product pest. The major digestive organ of larvae is the midgut, where a sharp $\mathrm{pH}$ gradient is found, from 5.6 in the anterior midgut (AM) to 7.9 in the posterior midgut (PM) (Terra et al., 1985; Vinokurov et al., 2006a; Elpidina and Goptar, 2007). This gradient restricts the activity of different digestive enzymes to specific compartments of the midgut, usually consistent with the $\mathrm{pH}$-optima of their activity (Vinokurov et al, 2006b). The major digestive peptidases in the AM of T. molitor larvae are cysteine peptidases (Terra and Cristofoletti, 1996; Vinokurov et al., 2006a, 2006b; Prabhakar et al., 2007). Serine peptidases are active in the PM of T. molitor larvae, including four trypsin-like and five chymotrypsin-like serine peptidases (Elpidina et al., 2005; Tsybina et al., 2005; Vinokurov et al., 2006a, 2006b), as well as a membrane-bound aminopeptidase (Cristofoletti and Terra, 1999, 2000) and soluble carboxypeptidase (Ferreira et al., 1990; Prabhakar et al., 2007).

The major dietary proteins of T. molitor larvae, prolamins, contain 30 to 50\% glutamine and 10 to $30 \%$ proline residues (Shewry and Tatham, 1990; Shewry and Halford, 2002). Therefore, we analyzed the major post-glutamine cleaving activities in the T. molitor larval digestive complex and found that they were cysteine 
peptidases (Goptar et al., 2012). Based on the composition of the insects' diet, we also predicted the occurrence of digestive PSP in T. molitor larvae. Previously we isolated and described the first proline-specific digestive peptidase in the midgut, which was a serine proline carboxypeptidase (PRCP) located mainly in the AM contents (Goptar et al., 2008a, 2008b, 2013).

Herein, we describe the primary physico-chemical and enzymatic properties of the secreted digestive DPP 4 in T. molitor larvae, including localization, $\mathrm{pH}$-optimum and $\mathrm{pH}$-stability, substrate specificity and the effect of different types of inhibitors. The study contributes to our general studies of how this insect has adapted specific digestive enzymes for success in a specialized environment and food source. 


\section{Materials and methods}

\subsection{Materials}

Sephadex G-150 was from Pharmacia, Sweden. Peptide substrates Ala-Pro-pNA, AlaAla-pNA, and Z-Ala-Ala-Pro-pNA were synthesized according to standard procedures (Pennington and Dunn, 1995). Glp-Ala-Ala-Leu-pNA and Glp-Phe-AlapNA were obtained according to (Stepanov et al., 1985) and (Lyublinskaya et al., 1987). Gly-Pro-pNA, Arg-Pro-pNA, Lys(Abz)-Pro-Pro-pNA, Suc-Ala-Ala-Pro-PhepNA and Bz-Arg-pNA were from Bachem, Switzerland, and Ala-Pro-AMC was from GeneCust, Luxembourg. Gliadins were from MP Biomedicals, France. Inhibitors diisopropylfluorophosphate (DFP), $\quad N_{\alpha}$-tosyl-L-lysine chloromethyl ketone hydrochloride (TLCK), ethylenediaminetetraacetic acid (EDTA), bestatin, and chymostatin were from Sigma-Aldrich, USA; trans-epoxysuccinyl-L-leucylamido(4guanidino)butane (E-64) was from ICN Biomedicals, Germany; PMSF was from

Serva, Germany; pepstatin A and Z-Pro-prolinal were from ICN, USA; diprotin A and diprotin B were from Bachem, Switzerland; and sitagliptin and vildagliptin were from BioVision, USA. Recombinant human DPP 4 (rhDPP 4, GWB-4F23CF) was from GenWay Biotech, San Diego, USA.

\subsection{Preparation of enzyme extracts}

For enzyme purification and analysis of physico-chemical properties, the AM and PM from T. molitor larvae were isolated and homogenized as described previously (Goptar et al., 2013).

For localization studies, AM and PM sections were isolated from larvae and were split longitudinally. The contents were extruded and retained while the tissue was rinsed with $0.9 \%$ saline. The lumen contents or the gut tissues were pooled from 50 AM or PM (for each of four biological replicates) and were homogenized 
separately at $4^{\circ} \mathrm{C}$ in $500 \mu \mathrm{l}$ of double distilled water in a glass Dounce homogenizer and centrifuged for $1 \mathrm{~h}$ at $35,000 \mathrm{x}$. All fractions were stored at $-70^{\circ} \mathrm{C}$.

\subsection{Enzyme assays using chromogenic p-nitroanilide substrates}

Activities of peptidases with the chromogenic $p$-nitroanilide substrates were determined spectrophotometrically, according to (Erlanger et al., 1961) at $405 \mathrm{~nm}$, with an ELx808 Absorbance Microplate Reader (BioTek Instruments, Inc., USA), and calculated using the initial rates of hydrolysis.

All substrates were initially dissolved in dimethylformamide (DMF) at 10 or 20 $\mathrm{mM}$ concentration, and were used in the reaction at $0.25 \mathrm{mM}$ (for substrates Ala-PropNA, Ala-Ala-pNA, Z-Ala-Ala-Pro-pNA, Gly-Pro-pNA, Arg-Pro-pNA) or $0.5 \mathrm{mM}$ (for substrates Glp-Ala-Ala-Leu-pNA, Glp-Phe-Ala-pNA, Suc-Ala-Ala-Pro-Phe-pNA and Bz-Arg-pNA) concentrations. Five $\mu \mathrm{l}$ of stock substrate solutions were added to each microplate well containing $10-80 \mu 1$ of $T$. molitor enzymes $\left(\mathrm{A}_{280}=0.06\right.$ Optical Units (OU)), or $15 \mu \mathrm{l}$ of commercial rhDPP 4 (diluted 1:1000, according to the manufacturer protocol), or $5 \mu \mathrm{l}$ of extract from the T. molitor larval AM ( $\mathrm{A}_{280}=9.58$ OU) and 0.1 M universal acetate-phosphate-borate buffer (UB) (Frugoni, 1957), adjusted to $\mathrm{pH} 5.6$ or $\mathrm{pH}$ 7.9. For localization studies, we used an aliquot of T. molitor extract equal to 0.1 (i.e., 10\%) of each gut fraction. The total volume of the reaction mixture was $200 \mu \mathrm{l}$. The mixture was incubated at $37^{\circ} \mathrm{C}$, and the absorbance was measured periodically. Enzyme activity was calculated in nmoles/min on the linear part of the time and substrate concentration response curves. All assays were run in triplicate.

2.4. Enzyme assays using fluorogenic substrates 
Activities of peptidases with the fluorogenic Abz-substrate were determined at $\lambda_{\mathrm{ex}} 340 \mathrm{~nm}$ and $\lambda_{\mathrm{em}} 400 \mathrm{~nm}$ with a FLx800 Fluorescence Microplate Reader (BioTek Instruments, Inc., USA), and calculated as described in section 2.3. The substrates were initially dissolved in DMF at $3 \mathrm{mM}$ concentration, and the reaction was carried out as described in the section 2.3.

\subsection{Purification of the peptidase}

The clarified extract from 200 pooled AM sections $(3 \mathrm{ml})$ was incubated for 30 min with a mixture of inhibitors: $0.1 \mathrm{mM}$ TLCK, $0.1 \mathrm{mM}$ chymostatin and $1 \mu \mathrm{M}$ E-64 to prevent degradation with the main digestive enzymes: trypsin, chymotrypsin, and cysteine cathepsins, respectively (Elpidina et al., 2005; Tsybina et al., 2005; Vinokurov et al., 2006a, 2006b). The extract was then applied to a Sephadex G-150 column $(2.5 \times 120 \mathrm{~cm})$ equilibrated with $0.5 \mathrm{M} \mathrm{NaCl}$ in $0.01 \mathrm{M}$ phosphate buffer, $\mathrm{pH}$ 5.6, containing $0.02 \% \mathrm{NaN}_{3}$. Fractionation was performed at $4^{\circ} \mathrm{C}$. Fractions of $9.0 \mathrm{ml}$ were collected and analyzed for protein content spectrophotometrically at $280 \mathrm{~nm}$. Enzymatic activity in the fractions was assayed with $0.25 \mathrm{mM}$ or $0.5 \mathrm{mM}$ (see section 2.3) chromogenic substrates: DPP 4: Ala-Pro-pNA, pH 7.9; cysteine peptidases: GlpPhe-Ala-pNA, pH 5.6, 6 mM cysteine; trypsin: Bz-Arg-pNA, pH 7.9; chymotrypsin: Glp-Ala-Ala-Leu-pNA and Suc-Ala-Ala-Pro-Phe-pNA, pH 7.9, in $200 \mu \mathrm{l}$ aliquots as described in section 2.3. Active fractions corresponding to the major peak of DPP 4 activity were pooled, desalted and concentrated on an Amicon YM30 membrane (Amicon, Netherlands) at $4^{\circ} \mathrm{C}$, and used immediately for further analysis, or were stored at $-70^{\circ} \mathrm{C}$.

The pooled fraction of DPP 4 was applied to a FPLC Phenyl-Sepharose column (Pharmacia, Sweden), equilibrated with $10 \mathrm{mM}$ phosphate buffer, $\mathrm{pH}$ 6.8, containing $1.7 \mathrm{M}\left(\mathrm{NH}_{4}\right)_{2} \mathrm{SO}_{4}$ and $0.02 \% \mathrm{NaN}_{3}$. The elution was performed in the same buffer in a $1.7-0 \mathrm{M}$ gradient of $\left(\mathrm{NH}_{4}\right)_{2} \mathrm{SO}_{4}$ with steps $100 \%(1.7 \mathrm{M})$ to $10 \%(0.17 \mathrm{M})$ to $5 \%$ 
$(0.085 \mathrm{M})$ to $0 \%(0 \mathrm{M})\left(\mathrm{NH}_{4}\right)_{2} \mathrm{SO}_{4}$. The eluate was collected in $1.0 \mathrm{ml}$ fractions. Protein content and enzyme activity were determined as described above.

Active fractions were loaded onto a FPLC Mono Q column (Pharmacia, Sweden), equilibrated with $10 \mathrm{mM}$ phosphate buffer, $\mathrm{pH}$ 6.8. The elution was performed in the same buffer in $0-1 \mathrm{M}$ gradient of $\mathrm{NaCl}$ with steps $0 \%(0 \mathrm{M})$ to $20 \%$ $(0.2 \mathrm{M})$ to $25 \%(0.25 \mathrm{M})$ to $30 \%(0.3 \mathrm{M})$ to $100 \%(1 \mathrm{M}) \mathrm{NaCl}$. Protein content and enzyme activity were determined as described above.

\subsection{Effect of pH on DPP 4 activity and stability}

The activity of DPP 4 in the purified preparation was measured in the $\mathrm{pH}$ range from 2 to 10 , at $0.5 \mathrm{pH}$ intervals, in $0.1 \mathrm{M} \mathrm{UB}$ as described in section 2.3, using AlaPro-pNA.

The $\mathrm{pH}$-stability of the enzyme was tested during $2 \mathrm{~h}$ incubations in $0.1 \mathrm{M} \mathrm{UB}$, with $\mathrm{pH}$ ranging from 2 to 10 at 0.5 intervals. After $2 \mathrm{~h}$, the $\mathrm{pH}$ of all samples was adjusted to a value of 7.9 , and the activity was measured as described above.

\subsection{Substrate specificity}

Substrate specificity was studied using the chromogenic substrates Ala-PropNA, Gly-Pro-pNA, Arg-Pro-pNA, Ala-Ala-pNA, Z-Ala-Ala-Pro-pNA and with the

fluorogenic substrate Lys(Abz)-Pro-Pro-pNA, as described in sections 2.3 and 2.4. T. molitor and human DPP 4 substrate specificity was calculated as the percent of activity with Ala-Pro-pNA. 
Gliadin proteolysis was measured by the increase in free amino groups with 2,4,6-trinitrobenzene sulfonic acid (TNBS) (Fields, 1972). For a comparative assay of activity, the amounts of TmDPP 4 and rhDPP 4 added to the reaction mixture were equalized by activity units (as determined by hydrolysis of the substrate Ala-Pro-pNA in the presence of $2 \mathrm{M}$ urea). The reaction mixture included $750 \mu \mathrm{g}$ of gliadins dissolved in 0.1 M UB, pH 7.9, 3 mM DTT, $2 \mathrm{M}$ urea and TmDPP 4 purified enzyme $\left(\mathrm{A}_{280}=2.1 \mathrm{OU}, 90 \mu \mathrm{l}\right)$ or commercial rhDPP 4 (diluted 1:1000, $\left.147 \mu \mathrm{l}\right)$. The final volume was $307.5 \mu 1$. Twenty $\mu$ l of reaction mixture for each enzyme was removed at time zero, and at $7 \mathrm{~min}$ intervals over a $35 \mathrm{~min}$ incubation period at $37^{\circ} \mathrm{C}$. The reaction with TNBS was carried out immediately, according to the protocol (Fields, 1972). The optical absorbance of the colored reaction product was measured at 405 nm with a microplate reader.

\subsection{Effect of inhibitors and activators}

Effector sensitivity was studied using EDTA, DFP, PMSF, diprotin B and cysteine at concentrations from 0.1 to $10 \mathrm{mM}$; pepstatin A and E-64 from 0.001 to 0.1 $\mathrm{mM}$; Z-Pro-prolinal, bestatin, and diprotin A from 0.01 to $1 \mathrm{mM}$; and sitagliptin and vildagliptin from 0.05 to $10 \mu \mathrm{M}$. Preincubations for 20 min included 10-80 $\mu \mathrm{l}$ of $T$. molitor enzyme $\left(\mathrm{A}_{280}=0.06 \mathrm{OU}\right)$ or $15 \mu \mathrm{l}$ of commercial rhDPP 4 (diluted 1:1000) and the inhibitor in $0.1 \mathrm{M} \mathrm{UB}, \mathrm{pH} 7.9$, at room temperature. Activity was measured as described in section 2.3, using Ala-Pro-pNA. The effect of class-specific inhibitors was the percent of residual enzyme activity, and DPP 4-specific inhibitors were compared by the concentration that resulted in 50\% inhibition of proteolytic activity $\left(\mathrm{IC}_{50}\right)$.

2.10. Electrophoretic studies and postelectrophoretic testing of the activity 
Electrophoresis was carried out under native conditions in $8 \%$ polyacrylamide gels containing $35 \mathrm{mM}$ HEPES and $43 \mathrm{mM}$ imidazole at $\mathrm{pH} \mathrm{7.2,} \mathrm{according} \mathrm{to}$ (McLellan, 1982). An aliquot of enzyme with predetermined activity of $1 \mathrm{nmole} / \mathrm{min}$ was added to each well. Electrophoresis was performed toward the anode and cathode at a constant current of $20 \mathrm{~mA}$ for $60 \mathrm{~min}$ at $4^{\circ} \mathrm{C}$.

Postelectrophoretic detection of specific proteolytic activity was performed directly in the native gel with the specific fluorogenic substrate Ala-Pro-AMC. After electrophoresis, the resolving gel was incubated with $0.125 \mathrm{mM}$ substrate in $0.1 \mathrm{M}$ $\mathrm{UB}, \mathrm{pH} 7.9$, for $10 \mathrm{~min}$. Fluorescent bands of the reaction product were observed at $366 \mathrm{~nm}$ and photographed.

\subsection{Mass spectrometry analysis}

Mass spectrometry analysis was performed as described previously (Prabhakar et al., 2007). The purified peptidase preparation was subjected to native PAGE as described in section 2.10, and the stained protein band, corresponding to the fluorescent proteolytic activity band with the substrate Ala-Pro-AMC in a parallel lane, was excised and subjected to in-gel tryptic hydrolysis and analyzed by MALDITOF MS and MS/MS. Mass spectra were recorded on an Ultraflextreme MALDITOF-TOF mass spectrometer (Bruker Daltonik, Bremen, Germany) equipped with a UV laser $(\mathrm{Nd})$, and obtained in the positive ion mode using the reflectron. The accuracy of the measured masses after additional calibration using trypsin autolysis peaks was $30 \mathrm{ppm}$. Fragmentation spectra were obtained in the tandem mode LIFT, and the mass measurement accuracy of fragments was within $1 \mathrm{Da}$. The mass spectra were submitted to the Mascot Server (http://www.matrixscience.com) and a custom

database with the sequences from the transcriptome database of the T. molitor larvae gut (Martynov et al., 2015). 


\subsection{Bioinformatics analysis}

The amino acid sequence of TmDPP 4 was predicted from mRNA sequences in the larval gut transcriptome (Martynov et al., 2015). To identify open reading frames (ORFs) from the T. molitor larvae gut transcriptome that were homologous to human

DPP 4 (NP_001926, P27487), we used the algorithm BLAST (blastp) (http://blast.ncbi.nlm.nih.gov/Blast.cgi) and a number of custom scripts (Martynov et al., 2015). We constructed multiple alignments from pairwise alignments of predicted protein sequences, using custom scripts based on the algorithm of Wagner-Fischer (Wagner and Fischer, 1974). ORFs that were grouped into blocks with identity of at least $95 \%$ and that overlapped with another block of at least 10 amino acid residues were considered as referring to one unique peptidase. Multiple sequence alignment (MAFFT) (Katoh et al., 2005) and custom scripts were used to refine and build consensus sequences.

A multiple alignment of different DPP 4 sequences was performed using ClustalW (http://www.ebi.ac.uk/Tools/clustalw2/index.html) (Larkin et al., 2007) and visualized in GeneDoc (Nicholas et al., 1997). Identification of a signal peptide was with SignalP (http://www.cbs.dtu.dk/services/SignalP/) (Petersen et al., 2011).

Modeling of TmDPP 4 three-dimensional structure was performed in the SWISS-MODEL server using the default settings of the program (Biasini et al., 2014). 


\section{Results}

\subsection{Localization of T. molitor DPP 4}

Because digestive enzymes in the $T$. molitor larval midgut are compartmentalized in a $\mathrm{pH}$ gradient from 5.6 in the $\mathrm{AM}$ to 7.9 in the $\mathrm{PM}$, we measured the activity of DPP 4 separately in the AM and PM, and in gut contents and gut tissues. Gut contents were fractionated to soluble fractions containing activities of secreted digestive enzymes, and insoluble fractions, which can contain enzymes adsorbed onto the food remnants, and residual food enzymes.

At first we measured the activity of DPP 4 under physiological $\mathrm{pH}$ in soluble and insoluble fractions of the gut as well as gut tissues, and calculated the specific activity per gut. In the AM, activity measurements were performed at $\mathrm{pH} 5.6$, and in the PM, activity was measured at pH 7.9 (Vinokurov et al., 2006a). The major DPP 4 activity in either section was from fractions containing soluble secreted enzyme. Soluble DPP 4 activity was 1.5 -fold higher in the PM than in the AM, measured under the physiological $\mathrm{pH}$ for each gut section (Table 1). In the AM, the fraction of soluble secreted enzymes contained $83 \%$ of the total DPP 4 activity, and in the PM 55\% of the total DPP 4 activity was found in the soluble fraction. We then measured DPP 4 activity in the AM fraction at the optimal $\mathrm{pH}$ for DPP 4 activity, (7.9) and found that activity in the soluble extract increased 2.2-fold, and exceeded the corresponding activity in the PM.

Enzymes from other fractions made smaller contributions to the total DPP 4 activity (Table 1). The activity of insoluble gut contents did not exceed $10 \%$ in all cases. The activity of DPP 4 in tissue fractions from the AM was $11 \%$ of the total at $\mathrm{pH} 5.6$ and $15 \%$ at $\mathrm{pH}$ 7.9. However, in the PM tissues the contribution of DPP 4 activity at $\mathrm{pH} 7.9$ was $36 \%$. Activity in the tissue fraction is likely due to another $T$. molitor DPP4 with a transmembrane domain, which we also identified in the $T$. molitor transcriptome data (unpublished data). 


\subsection{Purification of T. molitor DPP 4}

Because the highest activity was obtained in AM fractions, we used a threestep chromatography process to purify TmDPP 4 from the larval AM. The first stage was gel filtration of the extract on a Sephadex G-150 column (Fig. 1A). Isolation was performed in the presence of trypsin, chymotrypsin and cysteine peptidase inhibitors, to prevent degradation of TmDPP 4 by other major digestive peptidases. Application of this type of chromatography effectively separated TmDPP 4, displaying a molecular mass of $170 \mathrm{kDa}$, from residual activity peaks of the major digestive serine and cysteine endopeptidases, with molecular masses less than $40 \mathrm{kDa}$ (data not shown).

TmDPP 4 was subjected to further purification on Phenyl-Sepharose column using linear $\left(\mathrm{NH}_{4}\right)_{2} \mathrm{SO}_{4}$ gradient with several steps (Fig. 1B). The major peak of TmDPP 4 activity that eluted at 5\% salt was further purified by anion exchange chromatography on MonoQ column (FPLC) (Fig. 1C). As a result, we obtained one main peak of peptidase activity, which eluted at $25 \% \mathrm{NaCl}$. Most contaminating proteins eluted at a $\mathrm{NaCl}$ concentration of more than $30 \%$. Fractions with DPP 4 activity were combined, concentrated and desalted.

Results of the TmDPP 4 purification process are summarized in Table 2. The purification ratio, based on the specific activity, increased at the stage of gelfiltration, and protein content significantly decreased. As a result of further purification on a Phenyl-Sepharose and MonoQ columns, purity increased substantially with a parallel significant decrease of protein, due to the removal of contaminating proteins. The enzyme was purified 530-fold, with a yield of $7 \%$.

\section{3. $p H$-optimum and pH-stability of T. molitor DPP 4}


The effect of $\mathrm{pH}$ on the activity and stability of TmDPP 4 was studied by hydrolysis of the substrate Ala-Pro-pNA. The T. molitor enzyme had a pH-optimum at pH 7.9 (Fig. 2A) and was stable in the pH-range 4.8 - 8.4 (Fig. 2B).

\subsection{Identification of T. molitor DPP 4 by mass-spectrometry}

We identified a putative DPP 4 sequence in the transcriptome from the $T$. molitor larval gut. TmDPP 4 mRNA was expressed at highest levels among other PSP mRNAs in the T. molitor gut transcriptome (unpublished data). To correlate this sequence to the purified $T$. molitor enzyme, we obtained a tryptic hydrolyzate of the purified protein in an electrophoretic band corresponding to active enzyme. Native electrophoresis of purified TmDPP 4 toward the anode at $\mathrm{pH} 7.2$ and postelectrophoretic analysis of activity with Ala-Pro-AMC indicated a single band of activity (Fig. 3A). There was no DPP 4 activity in the analysis of electrophoresis towards the cathode at $\mathrm{pH} 7.2$ (data not shown). The sample was submitted to massspectrometry, and the resulting MS and MS/MS profiles indicated identity with the predicted protein from the highly expressed mRNA of TmDPP 4, with a reliable score of 471 (Fig. 3B). The protein contained 768 amino acid residues with the $\mathrm{Mm}$ 86,575 $\mathrm{Da}$, and predicted pI 4.7. Therefore, the active enzyme in the gut extract with $\mathrm{Mm} 170 \mathrm{kDa}$ (according to gel-filtration data) was present in the dimeric form.

\subsection{Structural analysis}

Alignment of insect and mammalian DPP 4 (EC 3.4.14.5) revealed highly conserved domains (Fig. 4). DPP 4 enzymes from T. molitor and a closely related tenebrionid Tribolium castaneum have similar predicted signal peptides, which suggest that these enzymes are secreted. Human, rat and mouse enzymes have no signal peptides, but instead have transmembrane domains. The active site of human DPP 4 consists of Ser630, Asp708, His740 (Misumi et al., 1992), and is conserved for 
all studied organisms. Core substrate binding sites: S1 subsite - Asn710 (hereinafter human DPP 4 numbering), and S2 subsite - Arg125, Glu205, Glu206, Tyr662, Asp663 (Meadows et al., 2007) also are highly conserved. Significant differences were observed in residues adjacent to the S2 subsite - in the "S2 extensive subsite" Val207, Ser209, Phe357, Arg358 (Nabeno et al., 2013). Homologous replacements of Val207Ile in rat and Ser209Gly in all other mammalian and insect DPP 4 were found, as well as nonhomologous replacement Arg358Glu and deletion of Phe357 in both insect sequences.

We have obtained a model of the three-dimensional structure of TmDPP 4 based on the homology alignment of the template protein sequences with known crystal structures and the predicted protein (Fig. 5A). Like human DPP 4 (Hiramatsu et al., 2003; Rasmussen et al., 2003; Thoma et al., 2003; Aertgeerts et al., 2004), TmDPP 4 also consists of two domains, the catalytic domain, with an $\alpha / \beta$ hydrolase fold, and an eight-bladed $\beta$ propeller domain with an 8 -fold repeat of a four-strand $\beta$ sheet motif (Fig. 5A,B). Human DPP 4 has five disulfide bonds (Rasmussen et al., 2003). Analysis of the human DPP 4 crystal structure revealed that four are located in the $\beta$-propeller domain and one in the catalytic domain (Fig. 5B red circles). The human enzyme has two cysteine amino acid residues, which are not involved in disulfide bond formation (Cys301 and Cys551), and are directed into the cavity, forming the substrate-binding site (Fig. 5B blue circles). In contrast to the human enzyme, TmDPP 4 possesses only six cysteine residues, involved in the formation of three disulfide bridges, arranged in the $\beta$-propeller domain (Fig. 5A red circles).

\subsection{Substrate specificity}

The substrate specificity of TmDPP 4 was studied in parallel to the bestcharacterized human enzyme, recombinant human DPP 4 (rhDPP 4), using peptide substrates of different length and structure. We used substrates with Pro or Ala in the 
P1 position, various residues in P2, Pro in P', and with a free N-terminus: Ala-PropNA, Gly-Pro-pNA, Arg-Pro-pNA, Ala-Ala-pNA and Lys(Abz)-Pro-Pro-pNA; and with blocked N-terminus Z-Ala-Ala-Pro-pNA.

Arg-Pro-pNA was hydrolyzed more efficiently by TmDPP 4 than Ala-PropNA and Gly-Pro-pNA (Fig. 6). The human enzyme hydrolyzed Arg-Pro-pNA and Ala-Pro-pNA with comparable rates. Substrates with Ala in the P1 position, as well as N-blocked prolyl oligopeptidase (POP) and PRCP substrate Z-Ala-Ala-Pro-pNA, were hydrolyzed much slower, and the substrate Lys(Abz)-Pro-Pro-pNA with Pro in position P' was not hydrolyzed by either T. molitor or human DPP 4.

\subsection{Proteolysis of gliadins}

Cereal gliadins are the major dietary proteins of $T$. molitor larvae. To understand the biological function of TmDPP 4, we evaluated the effect of the insect and mammalian enzymes on gliadin hydrolysis, monitored by the release of $\mathrm{NH}_{2}$ groups with TNBS. The experiment demonstrated that TmDPP 4 cleaved gliadins four-fold more efficiently than rhDPP 4 (Fig. 7).

\subsection{Effect of inhibitors and activators}

The effect of inhibitors was studied with class-specific inhibitors of different peptidases, and specific reversible inhibitors of DPP 4 . The activity of TmDPP 4 was suppressed by inhibitors of serine peptidases DFP and PMSF (Table 3). Inhibitors of peptidases of other classes - cysteine, aspartyl and metallopeptidases (E-64, pepstatin A and EDTA, respectively) had no significant effect on enzyme activity. Specific inhibitors of prolyl oligopeptidases (Z-Pro-prolinal) and aminopeptidases (bestatin) also had little effect on the activity of DPP 4. An activator of SH-dependent enzymes, cysteine, had no effect on TmDPP 4 activity. 
The effect of specific inhibitors of DPP 4 (diprotin A, diprotin B, sitagliptin, vildagliptin) on T. molitor and human DPP 4 activities was compared, and a similar inhibition tendency was observed for both enzymes (Table 4). While DFP inhibited both human and insect enzymes with comparable maximum efficiency, other inhibitors were less effective toward the insect enzyme, as $\mathrm{IC}_{50}$ values were 4 to 7 times higher than with the mammalian enzyme, and sitagliptin had a negligible effect on T. molitor DPP 4. Among the specific inhibitors, vildagliptin was most effective toward both human and insect enzymes. 


\section{Discussion}

This paper is devoted to the purification and characterization of the first soluble DPP 4 with a digestive function, found in the larval midgut of an insect, $T$. molitor. To date, there is little information about insect DPP 4 in the literature. The enzyme was partially purified from the cockroach brain and intestine (Nassel et al., 2000). In addition, there is a report of a Drosophila melanogaster gene product, which was identified as DPP 4 (Chihara et al., 2005). However, these enzymes have not been characterized as to function or otherwise.

The physico-chemical properties of the enzyme were revealed by the study of the effect of $\mathrm{pH}$ on the activity and stability of TmDPP 4, substrate specificity, and inhibitor sensitivity. A digestive function of the enzyme was substantiated by localization studies and the ability to hydrolyze the main dietary proteins of the insect. Analysis of primary and predicted 3D structures of the TmDPP 4 revealed differences between insect and human enzymes that relate to structure and function. However, the general properties of the T. molitor enzyme are similar to human DPP 4. Both are active in the dimeric form, with a $\mathrm{Mm}$ of $170 \mathrm{kDa}$, and similar $\mathrm{pH}$ optima and stability (Yoshimoto et al., 1978).

Identification of the primary structure of the purified T. molitor enzyme was performed by mass spectrometry analysis using a predicted DPP 4 sequence from the larval gut transcriptome. Structural analysis of T. molitor DPP 4 revealed that the region of the active site is highly conserved in mammalian and insect enzymes. However, the insect DPP 4 has a signal peptide, which suggests that it is a secreted enzyme and therefore likely secreted into the gut lumen to participate in digestion of food, as it was localized mainly in the soluble gut contents. Mammalian DPP 4 lack a signal peptide, and thus as a transmembrane enzyme have a function distinct from the insect enzyme. 
The high degree of sequence similarity between T. molitor and human enzyme was used for modelling the 3D structure of insect enzyme. Similar to the human enzyme (Hiramatsu et al., 2003; Rasmussen et al., 2003; Thoma et al., 2003; Aertgeerts et al., 2004), TmDPP 4 consists of two domains: the catalytic domain, with an $\alpha / \beta$ hydrolase fold, and $\beta$ propeller domain with an 8 -fold repeat of a fourstrand $\beta$ sheet motif. However, while human DPP 4 has five disulfide bonds, TmDPP 4 has only three, lacking one in the $\beta$ propeller domain and the other in the catalytic domain. Additionally, TmDPP 4 has no free Cys residues, in agreement with the biochemical data on the absence of increased activity in buffers containing cysteine.

TmDPP 4 contains the same residues in the active site and S1 and S2 subsites as all mammalian enzymes. Conservation was observed also in Glu205 and Glu206 residues and their surrounding consensus regions DW(V/L)YEEE, located on the $\mathrm{N}$ terminus of the DPP 4 sequence, which are characteristic for serine peptidases of the S9B subfamily and are important for their activity. Residues beyond the S2 subsite the "S2 extensive subsite": Val207, Ser209, Phe357, Arg358 - were important for interaction of human DPP 4 with specific inhibitors including those that are substratelike (Nabeno et al., 2013). We observed significant differences in amino acid residues of the "S2 extensive subsite" in TmDPP 4 compared to mammalian enzymes: nonsynonymous replacement Arg358Glu and deletion of Phe357. These differences presumably affect substrate specificity and inhibitor sensitivity, based on our comparative studies.

Our study of the substrate specificity of the purified TmDPP 4 confirmed the specificity of insect DPP 4 to a Pro residue in P1 position. TmDPP 4 and rhDPP 4 primarily differ in their preference for the P2 position of the substrate. The most specific substrate for TmDPP 4 was the N-free substrate Arg-Pro-pNA. Classical substrates Ala-Pro-pNA and Gly-Pro-pNA, which are typically used to detect DPP 4 activity, were hydrolyzed considerably slower than Arg-Pro-pNA, while rhDPP 4 did not prefer Arg-Pro-pNA, and hydrolyzed Gly-Pro-pNA much better than TmDPP 4. 
The preference of TmDPP 4 for the substrate Arg-Pro-pNA is apparently connected with the replacement Arg358Glu in the S2 extensive subsite of TmDPP 4. The substrates with a protective blocking group Z-, used to determine activity of PRCP, POP and PEP, were not hydrolyzed, indicating that the activity belongs to the pure DPP 4 enzyme.

The effect of class-specific inhibitors of serine-, cysteine-, aspartic- and metallopeptidases was typical as for serine peptidases: TmDPP 4 was sensitive only to inhibitors of serine peptidases. Specific inhibitors of DPP 4 (diprotin A, diprotin B and vildagliptin) inhibited T. molitor DPP 4 four to seven times less than rhDPP 4 . Furthermore, sitagliptin, one of the most effective inhibitors of rhDPP 4, had practically no effect on T. molitor DPP 4. Authors (Nabeno et al., 2013) studied the relationship between the activity of different inhibitors and the mode of their binding to DPP 4, based on analysis of co-crystal structures of inhibitors with DPP 4, studying in detail vildagliptin and sitagliptin. These two inhibitors belong to different types of inhibitor classes, and thus have a different mode of action with the enzyme. Vildagliptin is a peptide mimetic, and it binds to the S1 and S2 subsites of DPP 4. Sitagliptin has a different structure, and it binds to the S1 subsite and to the residues beyond the S2 subsite - the "S2 extensive subsite". We propose that significant differences in the effect of sitagliptin on human and T. molitor DPP 4 are due to differences in the structures of this extensive subsite.

Human membrane DPP 4 is a surface antigen of T-lymphocytes CD26, a marker of various diseases, and is an important member of processes related to the degradation of proline-containing peptides. Among the natural substrates, human DPP 4 hydrolyzes N-terminal Arg-Pro from substance P, Thr-Pro from kentsin, and Tyr-Pro from casomorphin (Puschel et al., 1982). Human DPP 4 also cleaves Nterminal His-Ala and Tyr-Ala from biologically active glucagon-like peptide-1 (GLP1) and gastric inhibitory polypeptide (GIP), which stimulate production of insulin. Our research has shown that TmDPP 4 is a soluble enzyme located in the insect 
larval gut lumen, which suggests that it performs digestive function. We added additional evidence to this theory, in that TmDPP 4 hydrolyzed the major natural dietary proteins for this insect, gliadins, almost four-fold more efficiently than rhDPP 4. The dipeptide substrate with a small Ala P2 residue binds to DPP 4 at S1 and S2 core substrate binding subsites, which are highly conservative in human and TmDPP4. In contrast to the short substrates the binding of long protein substrates may substantially differ due to differences in the "S2 extensive subsite" structures. The difference in gliadin hydrolysis efficiency is presumably evolutionally determined due to the specific digestive function of TmDPP4 in contrast to membrane human DPP 4. Given the close homology and dietary preference of $T$. castaneum, this enzyme likely has a similar role in closely related beetles. However, it is unknown if DPP 4 is involved in digestion in other animals. More studies are needed to analyze the role of DPP 4 in the hydrolysis of foods rich in proline residues in other biological systems.

\section{Conclusion}

T. molitor DPP 4 is the first identified soluble digestive DPP 4 in insects. In this report, we demonstrate that $T$. molitor larval DPP 4 effectively participates in gliadin hydrolysis, the main dietary protein of the insect. Thus, we have now identified an additional PSP, following the first soluble digestive PSP, PRCP (Goptar et al., 2013). Our combined data indicate that TmDPP 4 and PRCP participate in the complex degradation of gliadins following the preliminary degradation by endopeptidases. These data provide a comprehensive overview of protein digestion in tenebrionid larvae for the development of new insect control products and further the

understanding of the evolution of enzymes in insects to adapt to specific dietary niches. 


\section{Acknowledgements}

Mention of trade names or commercial products in this publication is solely for the purpose of providing specific information and does not imply recommendation or endorsement by the U.S. Department of Agriculture. USDA is an equal opportunity provider and employer.

\section{Funding information}

The research was performed with the support of the Russian Foundation for Basic Research (grants \#14-04-91167-NSFC_a, 15-04-08689-a, 15-03-06675-a and 16-34-01012 mol_a). The MALDI MS facility became available to us under the framework of the Moscow State University Development Program PNG 5.13.

\section{Authors' contributions}

VFT performed study of physico-chemical properties, localization, gliadins hydrolysis, comparative studies and wrote the manuscript. IAG and IAK performed isolation of TmDPP 4 and study of physico-chemical properties. DPZ performed fractionation of $T$. molitor larvae guts. MVS performed MS analysis. MAB supervised activity tests. YED performed chromatography purification and supervised gliadins hydrolysis tests. BO provided the transcriptome database and participated in the writing of the manuscript. IYF participated in the design of the experiment, directed the analysis of the data, designed and provided the substrates and participated in the writing of the manuscript. ENE led the design of the experiment, analysis of the data, and writing of the manuscript. 


\section{References}

Aertgeerts, K., Ye, S., Tennant, M.G., Kraus, M.L., Rogers, J., Sang, B.C., Skene, R.J., Webb, D.R., Prasad, G.S., 2004. Crystal structure of human dipeptidyl peptidase IV in complex with a decapeptide reveals details on substrate specificity and tetrahedral intermediate formation. Protein Sci. 13(2), 412-421.

Biasini, M., Bienert, S., Waterhouse, A., Arnold, K., Studer, G., Schmidt, T., Kiefer, F., Cassarino, T.G., Bertoni, M., Bordoli, L., Schwede, T., 2014. SWISSMODEL: modelling protein tertiary and quaternary structure using evolutionary information. Nucleic Acids Research 42(W1), W252-W258.

Chihara, C.J., Song, C., La Monte, G., Fetalvero, K., Hinchman, K., Phan, H., Pineda, M., Robinson, K., Schneider, G.P., 2005. Identification and partial characterization of the enzyme of omega: one of five putative DPP IV genes in Drosophila melanogaster. J. Insect Sci. 5, 25pp.

Cristofoletti, P.T., Terra, W.R., 1999. Specificity, anchoring, and subsites in the active center of a microvillar aminopeptidase purified from Tenebrio molitor (Coleoptera) midgut cells. Insect Biochem. Mol. Biol. 29, 807-819.

Cristofoletti, P.T., Terra, W.R., 2000. The role of amino acid residues in the active site of a midgut microvillar aminopeptidase from the beetle Tenebrio molitor. Biochim. Biophys. Acta 1479, 185-195.

Cunningham, D.F., O’Connor, B., 1997. Proline specific peptidases. Biochim. Biophys. Acta. 1343, 160-186.

David, F., Bernard, A.M., Pierres, M., Marguet, D., 1993. Identification of serine 624, aspartic acid 702, and histidine 734 as the catalytic triad residues of mouse dipeptidyl-peptidase IV (CD26). A member of a novel family of nonclassical serine hydrolases. J. Biol.Chem. 268, 17247-17252.

Davy, A., Thomsen, K.K., Juliano, M.A., Alves, L.C., Svendsen, I., Simpson, D.J., 2000. Purification and Characterization of Barley Dipeptidyl Peptidase IV. Plant Physiology. 122, 425-431.

Durinx, C., Lambeir, A.M., Bosmans, E., Falmagne, J.B., Berghmans, R., Haemers, A., Scharpe, S., De Meester, I., 2000. Molecular characterization of dipeptidyl peptidase activity in serum: soluble CD26/dipeptidyl peptidase IV is responsible for the release of X-Pro dipeptides. Eur. J. Biochem. 267, 5608-5613. Elpidina, E.N., Goptar, I.A., 2007. Digestive peptidases in Tenebrio molitor and possibility of use to treat celiac disease. Entomol. Res. 37, 139-147.

Elpidina, E.N., Tsybina, T.A., Dunaevsky, Y.E., Belozersky, M.A., Zhuzhikov, D.P., Oppert, B., 2005. A chymotrypsin-like proteinase from the midgut of Tenebrio molitor larvae. Biochimie 87, 771-779.

Erickson, R.H., Bella, A.M., Brophy, E.J., Kobata, A., Kim, Y.S., 1983. Purification and molecular characterization of rat intestinal brush border membrane dipeptidyl aminopeptidase IV. Biochim. Biophys. Acta. 756, 258-265. 
Erlanger, B.F., Kokowsky, N., Cohen, W., 1961. The preparation and properties of two new chromogenic substrates of trypsin. Arch. Biochem. Biophys. 95, 271-278. Ferreira, C., Bellinello, G.L., Ribeiro, A.F., Terra, W.R., 1990. Digestive enzymes associated with the glycocalyx, microvillar membranes and secretory vesicles from midgut cells of Tenebrio molitor larvae. Insect Biochem. 20, 839-847.

Fields, R., 1972. The rapid determination of amino groups with TNBS. Methods Enzymol. 25, 464-468.

Flentke, G.R., Munoz, E., Huber, B.T., Plaut, A.G., Kettner, C.A., Bachovchin, W.W., 1991. Inhibition of dipeptidyl aminopeptidase IV (DP-IV) by Xaa-boroPro dipeptides and use of these inhibitors to examine the role of DP-IV in T-cell function. Proc. Natl Acad. Sci. USA 88, 1556-1559.

Frugoni, J.A.C., 1957. Tampone universale di Britton e Robinson a forza ionica constante. Gazz. Chem. Ital. 87, 403-407.

Fukasawa, K.M., Fukasawa, K., Sahara, N., Harada, M., Kondo, Y., Nagatsu, I., 1981. Immunohistochemical localization of dipeptidyl aminopeptidase IV in rat kidney, liver, and salivary glands. J. Histochem. Cytochem. 29, 337-343.

Gazi, M.I., Cox, S.W., Clark, D.T., Eley, B.M., 1995. Comparison of host tissue and bacterial dipeptidyl peptidases in human gingival crevicular fluid by analytical isoelectric focusing. Arch. Oral Biol. 40, 731-736.

Goptar, I.A., Filippova, I.Y., Lysogorskaya, E.N., Oksenoit, E.S., Vinokurov, K.S., Zhuzhikov, D.P., Bulushova, N.V., Zalunin, I.A., Dunaevsky, Y.E., Belozersky, M.A., Oppert, B., Elpidina, E.N., 2008a. Localization of post-proline cleaving peptidases in Tenebrio molitor larval midgut. Biochimie. 90(3), 508-514.

Goptar, I.A., Kulemzina, I.A., Filippova, I.Yu., Lysogorskaia, E.N., Oksenoit, E.S., Zhuzhikov, D.P., Dunaevsky, Y.E., Belozersky, M.A., Elpidina, E.N., 2008b. Properties of post-proline cleaving enzymes from Tenebrio molitor. Russian J. Bioorg. Chem. 34(3), 280-285.

Goptar, I.A., Semashko, T.A., Danilenko, S.A., Lysogorskaya, E.N., Oksenoit, E.S., Zhuzhikov, D.P., Belozersky, M.A., Dunaevsky, Y.E., Oppert, B., Filippova, I.Yu., Elpidina, E.N., 2012. Cysteine digestive peptidases function as postglutamine cleaving enzymes in tenebrionid stored-product pests. Comp. Biochem. Physiol. 161B, 148-154.

Goptar, I.A., Shagin, D.A., Shagina, I.A., Mudrik, E.S., Smirnova, Y.A., Zhuzhikov, D.P., Belozersky, M.A., Dunaevsky, Y.E., Oppert, B., Filippova, I.Y., Elpidina, E.N., 2013. A digestive prolyl carboxypeptidase in Tenebrio molitor larvae. Insect Biochem Mol Biol. 43, 501-509.

Gorvel, J.P., Ferrero, A., Chambraud, L., Rigal, A., Bonicel, J., Maroux, S., 1991. Expression of sucrase-isomaltase and dipeptidylpeptidase IV in human small intestine and colon. Gastroenterology 101(3), 618-625.

Hiramatsu, H., Kyono, K., Higashiyama, Y., Fukushima, C., Shima, H., Sugiyama, S., Inaka, K., Yamamoto, A., Shimizu, R., 2003. The structure and function of 
human dipeptidyl peptidase IV, possessing a unique eight-bladed beta-propeller fold. Biochem. Biophys. Res. Commun. 302(4), 849-854.

Iwaki-Egawa, S., Watanabe, Y., Kikuya, Y., Fujimoto, Y., 1998. Dipeptidyl peptidase IV from human serum: purification, characterization, and N-terminal amino acid sequence. J. Biochem. 124, 428-433.

Jobin, M.-C., Martinez, G., Motard, J., Gottschalk, M., Grenier, D., 2005. Cloning, Purification, and Enzymatic Properties of Dipeptidyl Peptidase IV from the Swine Pathogen Streptococcus suis. J. Bacteriology 187, 795-799.

Kabashima, T., Yoshida, T., Ito, K., Yoshimoto, T., 1995. Cloning, sequencing, and expression of the dipeptidyl peptidase IV gene from Flavobacterium meningosepticum in Escherichia coli. Arch. Biochem. Biophys. 320, 123-128.

Katoh, K., Kuma, K., Toh, H., Miyata, T., 2005. MAFFT version 5: improvement in accuracy of multiple sequence alignment. Nucl Acids Res. 33, 511-518.

Kenny, A.J., Booth, A.G., George, S.G., Ingram, J., Kershaw, D., Wood, E.J., Young, A.R., 1976. Dipeptidyl peptidase IV, a kidney brush-border serine peptidase. Biochem. J. 157, 169-182.

Larkin, M.A., Blackshields, G., Brown, N.P., Chenna, R., McGettigan, P.A., McWilliam, H., Valentin, F., Wallace, I.M., Wilm, A., Lopez, R., Thompson, J.D., Gibson, T.J., Higgins, D.G., 2007. ClustalW and ClustalX version 2. Bioinformatics 23, 2947-2948.

Lyublinskaya, L.A., Haidu, I., Balandina, G.N., Filippova, I.Yu., Markaryan, A.N., Lysogorskaya, E.N., Oksenoit, E.S., Stepanov, V.M., 1987. $p$-Nitroanilides of pyroglutamylpeptides as chromogenic substrates of serine proteinases. Bioorg. Khim. 13, 748-753.

Martynov, A.G., Elpidina, E.N., Perkin, L., Oppert, B., 2015. Functional analysis of $\mathrm{C} 1$ family cysteine peptidases in the larval gut of Tenebrio molitor and Tribolium castaneum. BMC Genomics 16(1):75.

McLellan, T., 1982. Electrophoresis buffers for polyacrylamide gels at various $\mathrm{pH}$. Anal. Biochem. 126, 94-99.

Meadows, S.A., Edosada, C.Y., Mayeda, M., Tran, T., Quan, C., Raab, H., Wiesmann, Ch., Wolf, B.B., 2007. Ala657 and Conserved Active Site Residues Promote Fibroblast Activation Protein Endopeptidase Activity via Distinct Mechanisms of Transition State Stabilization. Biochemistry 46, 4598-4605.

Misumi, Y., Hayashi, Y., Arakawa, F., Ikehara, Y., 1992. Molecular cloning and sequence analysis of human dipeptidyl peptidase 4, a serine proteinase on the cell surface. Biochim. Biophys. Acta. 1131(3), 333-336.

Nabeno, M., Akahoshi, F., Kishida, H., Miyaguchi, I., Tanaka, Y., Ishii, S., Kadowaki, T., 2013. A comparative study of the binding modes of recently launched dipeptidyl peptidase 4 inhibitors in the active site. Biochem. Biophys. Res. Commun. 434, 191-196.

Nassel, D.R., Mentlein, R., Bollner, T., Karlsson, A., 2000. Proline-specific dipeptidyl peptidase activity in the cockroach brain and intestine: partial 
characterization, distribution, and inactivation of tachykinin-related peptides. J. Comp. Neurology 418, 81-92.

Nicholas, K.B., Nicholas Jr., H.B., Deerfield, D.W., 1997. GeneDoc: analysis and visualization of genetic variation. Embnew News 4, 14.

Pennington M.W., Dunn B.M., 1995. Peptide Synthesis Protocols. SpringerLink/Humana Press.

Petersen, T.N., Brunak, S., von Heijne, G., Nielsen, H., 2011. SignalP 4.0: discriminating signal peptides from transmembrane regions. Nat. Methods 8, 785786.

Prabhakar, S., Chen, M.S., Elpidina, E.N., Vinokurov, K.S., Smith, C.M., Marshall, J., Oppert, B., 2007. Sequence analysis and molecular characterization of larval midgut cDNA transcripts encoding peptidases from the yellow mealworm, Tenebrio molitor. Insect Mol. Biol. 16, 455-468.

Puschel, G., Mentlein, R., Heymann, E., 1982. Isolation and characterization of dipeptidyl peptidase IV from human placenta. Eur J Biochem. 126(2), 359-365. Rahfeld, J., Schierhorn, M., Hartrodt, B., Neubert, K., Heins, J., 1991. Are diprotin A (Ile-Pro-Ile) and diprotin B (Val-Pro-Leu) inhibitors or substrates of dipeptidyl peptidase IV. Biochim. Biophys. Acta. 1076(2), 314-316.

Rasmussen, H.B., Branner, S., Wiberg, F.C., Wagtmann, N., 2003. Crystal structure of human dipeptidyl peptidase IV/CD26 in complex with a substrate analog. Nat. Struct. Biol. 10(1), 19-25.

Rawlings, N.D., Waller, M., Barrett, A.J., Bateman, A., 2014. MEROPS: the database of proteolytic enzymes, their substrates and inhibitors. Nucleic Acids Res. 42, D503-D509.

Ronai, A.Z., Timar, J., Mako, E., Erdo, F., Gyarmati, Z., Toth, G., Orosz, G., Furst, S., Szekely, J.I., 1999. Diprotin A, an inhibitor of dipeptidyl aminopeptidase IV (EC 3.4.14.5) produces naloxone-reversible analgesia in rats. Life Sci. 64(2), 145-152.

Sakashita, H., Akahoshi, F., Kitajima, H., Tsutsumiuchi, R., Hayashi, Y., 2006. [(S)-gamma-(Arylamino)prolyl]thiazolidine compounds as a novel series of potent and stable DPP-IV inhibitors. Bioorg Med Chem. 14(11), 3662-3671.

Shewry P.R., Halford N.G., 2002. Cereal seed storage proteins: structures, properties and role in grain utilization. J Exp Bot. 53(370), 947-958.

Shewry, P.R., Tatham, A.S., 1990. The prolamin storage proteins of cereal seeds: structure and evolution. Biochem. J. 267, 1-12.

Shin, J.W., Jurisic, G., Detmar, M., 2008. Lymphatic-specific expression of dipeptidyl peptidase IV and its dual role in lymphatic endothelial function. Exp. Cell Res. 314, 3048-3056.

Stepanov, V.M., Lysogorskaya, E.N., Filippova, I.Yu, Oksenoit, E.S., Lyublinskaya, L.A., $1985 . \quad$ L-Pyroglutamyl-L-phenylalanyl-L-alanyne $p$ nitroanilide - a chromogenic substrate of thiol proteinases. Russian inventor's certificate no. 1198082. Byul. Izobr. 46 (in Russian). 
Tanaka, T., Camerini, D., Seed, B., Torimoto, Y., Dang, N.H., Kameoka, J., Dahlberg, H.N., Schlossman, S.F., Morimoto, C., 1992. Cloning and functional expression of the T cell activation antigen CD26, J. Immunol. 149, 481-486.

Terra, W.R., Cristofoletti, P.T., 1996. Midgut proteinases in three divergent species of Coleoptera. The major cysteine peptidase activity is cathepsin L. Comp. Biochem. Physiol. 113B, 725-730.

Terra, W.R., Ferreira, C., Bastos, F., 1985. Phylogenetic consideration of insect digestion. Disaccharidases and the spatial organization of digestion in the Tenebrio molitor larvae. Insect Biochem. 15, 443-449.

Thoma, R., Löffler, B., Stihle, M., Huber, W., Ruf, A., Hennig, M., 2003. Structural basis of proline-specific exopeptidase activity as observed in human dipeptidyl peptidase-IV. Structure 11(8), 947-959.

Tsybina, T.A., Dunaevsky, Y.E., Belozersky, M.A., Zhuzhikov, D.P., Oppert, B., Elpidina, E.N., 2005. Digestive proteinases of yellow mealworm (Tenebrio molitor) larvae: purification and characterization of a trypsin-like proteinase. Biochemistry (Moscow) 70, 370-377.

Umezawa, H., Aoyagi, T., Ogawa, K., Naganawa, H., Hamada, M., Takeuchi, T., 1984. Diprotins A and B, inhibitors of dipeptidyl aminopeptidase IV, produced by bacteria. J Antibiot (Tokyo) 37(4), 422-425.

Vinokurov, K.S., Elpidina, E.N., Oppert, B., Prabhakar, S., Zhuzhikov, D.P., Dunaevsky, Y.E., Belozersky, M.A., 2006a. Diversity of digestive proteinases in Tenebrio molitor (Coleoptera: Tenebrionidae) larvae. Comp. Biochem. Physiol. 145B, 126-137.

Vinokurov, K.S., Elpidina, E.N., Oppert, B., Prabhakar, S., Zhuzhikov, D.P., Dunaevsky, Y.E., Belozersky, M.A., 2006b. Fractionation of digestive proteinases from Tenebrio molitor (Coleoptera: Tenebrionidae) larvae and role in protein digestion. Comp. Biochem. Physiol. 145B, 138-146.

Vinokurov, K.S., Oppert, B., Elpidina, E.N., 2005. An overlay technique for postelectrophoretic analysis of proteinase spectra in complex mixtures using $p$ nitroanilide substrates. Anal Biochem. 337(1), 164-166.

Wagner, R.A., Fischer, M.J., 1974. The string-to-string correction problem. JACM 21, 168-173.

Yoshimoto, T., Fischl, M., Orlowski, R.C., Walter, R., 1978. Post-proline cleaving enzyme and post-proline dipeptidyl aminopeptidase. Comparison of two peptidases with high specificity for proline residues. J. Biol. Chem. 253, 37083716. 


\section{Figure Legends}

Figure 1. Purification of DPP 4 from the T. molitor larvae AM. Chromatography on Sephadex G-150 (A), Penyl-Sepharose (B) and MonoQ (C). Activity of DPP 4 was measured with Ala-Pro-pNA (closed squares) in 0.1 M UB, pH 7.9. Absorbance at $280 \mathrm{~nm}$ is line with hatch marks; solid line demarcates the step gradient of $\left(\mathrm{NH}_{4}\right)_{2} \mathrm{SO}_{4}$ (B) or $\mathrm{NaCl}(\mathbf{C})$.

Figure 2. Effect of $\mathrm{pH}$ on the activity (A) and stability (B) of TmDPP 4.

Figure 3. Mass-spectrometry analysis of TmDPP 4. A, native PAGE of the TmDPP 4 with postelectrophoretic detection of the enzyme activity with the fluorogenic substrate Ala-Pro-AMC at $\mathrm{pH}$ 7.9. B, mass-spectrum of the isolated enzyme; signal peaks correspond to peptides in red in Fig. 5.

Figure 4. Alignment of DPP 4 from T. molitor, T. castaneum (XP_975053.1), human (NP_001926, P27487), rat (P14740) and mouse (P28843). Peptides indicated by red letters were found by MALDI-TOF mass spectrometry, and the sequences of underlined peptides were determined by MS/MS analysis. Amino acid residues of the active center are shaded with green, the S1 subsite is yellow, the S2 subsite is dark gray, and the "S2 extensive subsite" is light gray. The signal peptides of T. molitor 
and T. castaneum DPP 4 are in green letters, and the transmembrane domains of human, rat and mouse DPP 4 are in blue letters.

Figure 5. 3D structures of DPP 4. A, comparison of human DPP 4 crystal structure (pdb1wcy) in grey, aligned with TmDDP 4 model in green. B, crystal structure of human DPP 4 (pdb1wcy); cysteine amino acid residues, involved in disulfide bonds formation in TmDDP 4 (A) and in human DPP 4 (B) are enclosed in red circles; free cysteine amino acid residues in human DPP 4 (B) are enclosed in blue circles.

Figure 6. Substrate specificity of TmDDP 4 (dark grey columns) and rhDPP 4 (light grey columns) as described in Section 2.7.

Figure 7. Proteolysis of gliadins by TmDPP 4 (black circles) and rhDPP 4 (white circles) as described in Section 2.8. 
Figure 1

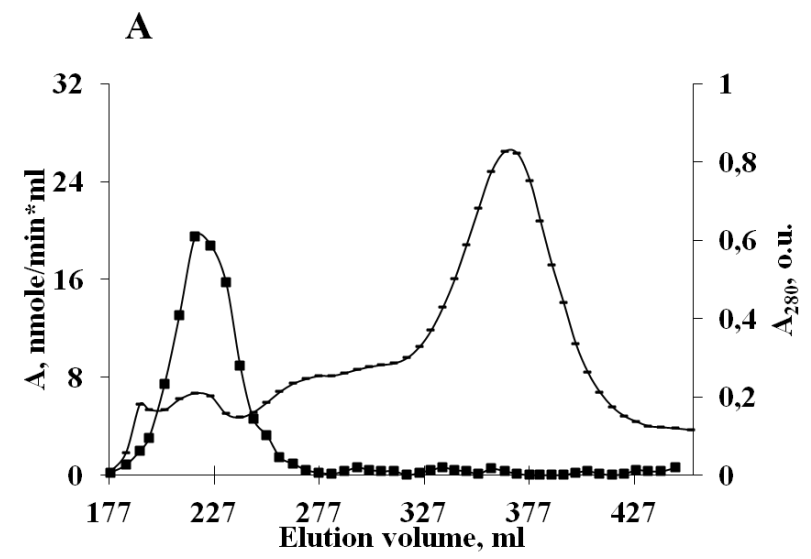

B

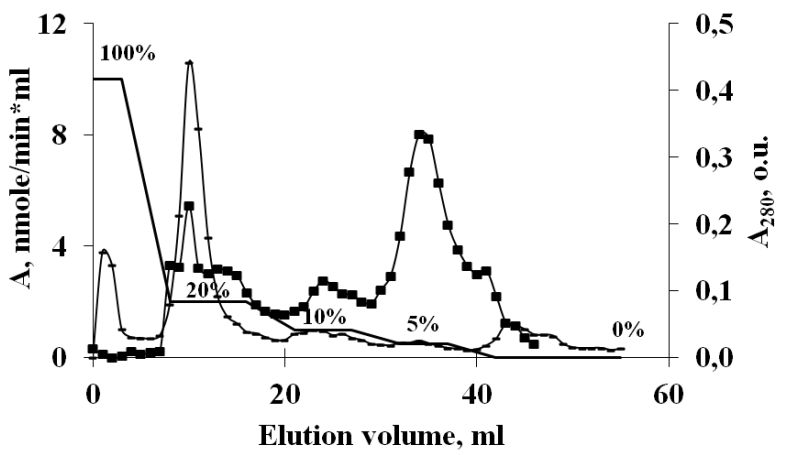

C

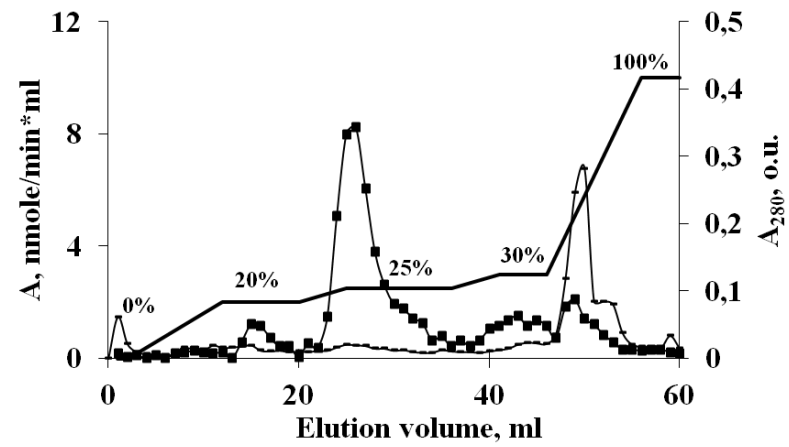


Figure 2
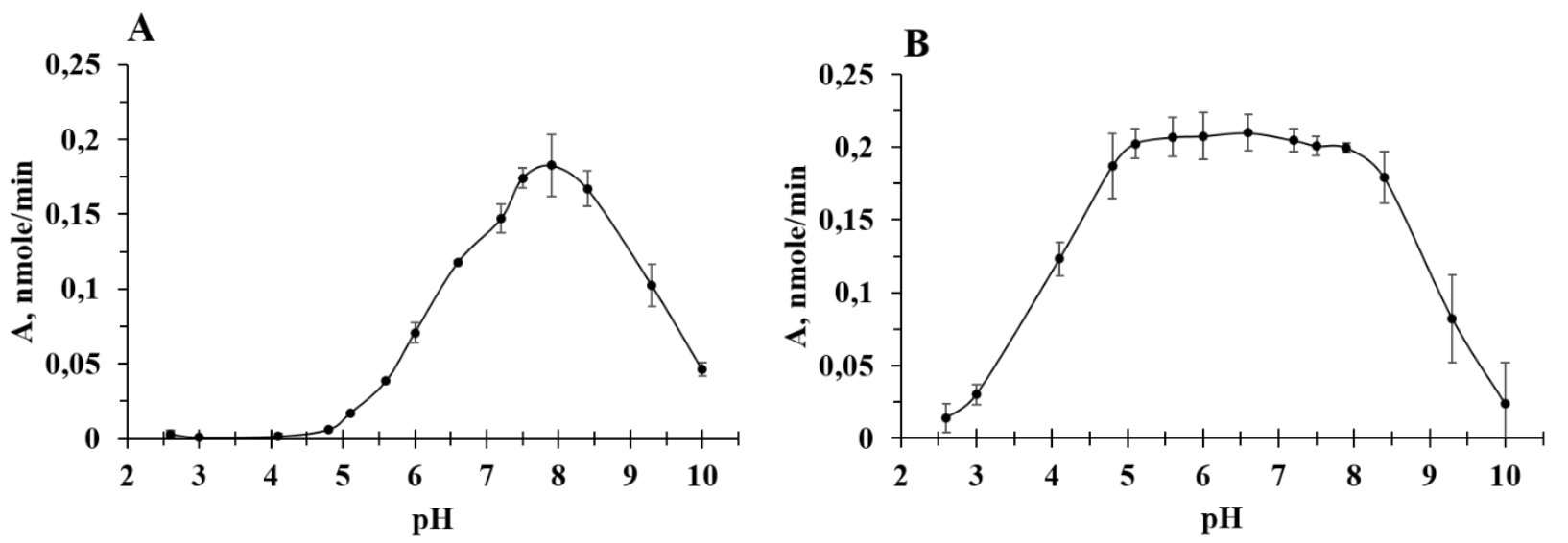
Figure 3

A $\quad$ B

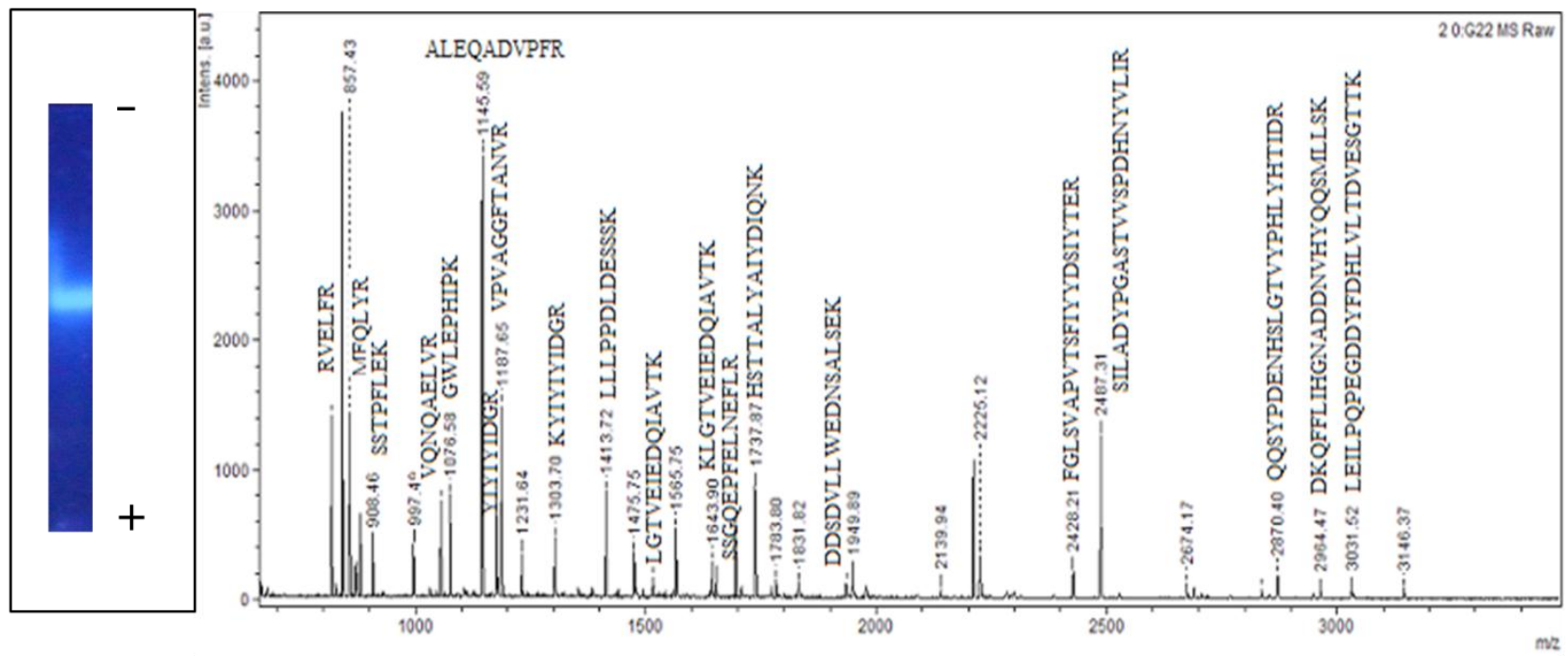




\section{Figure 4}

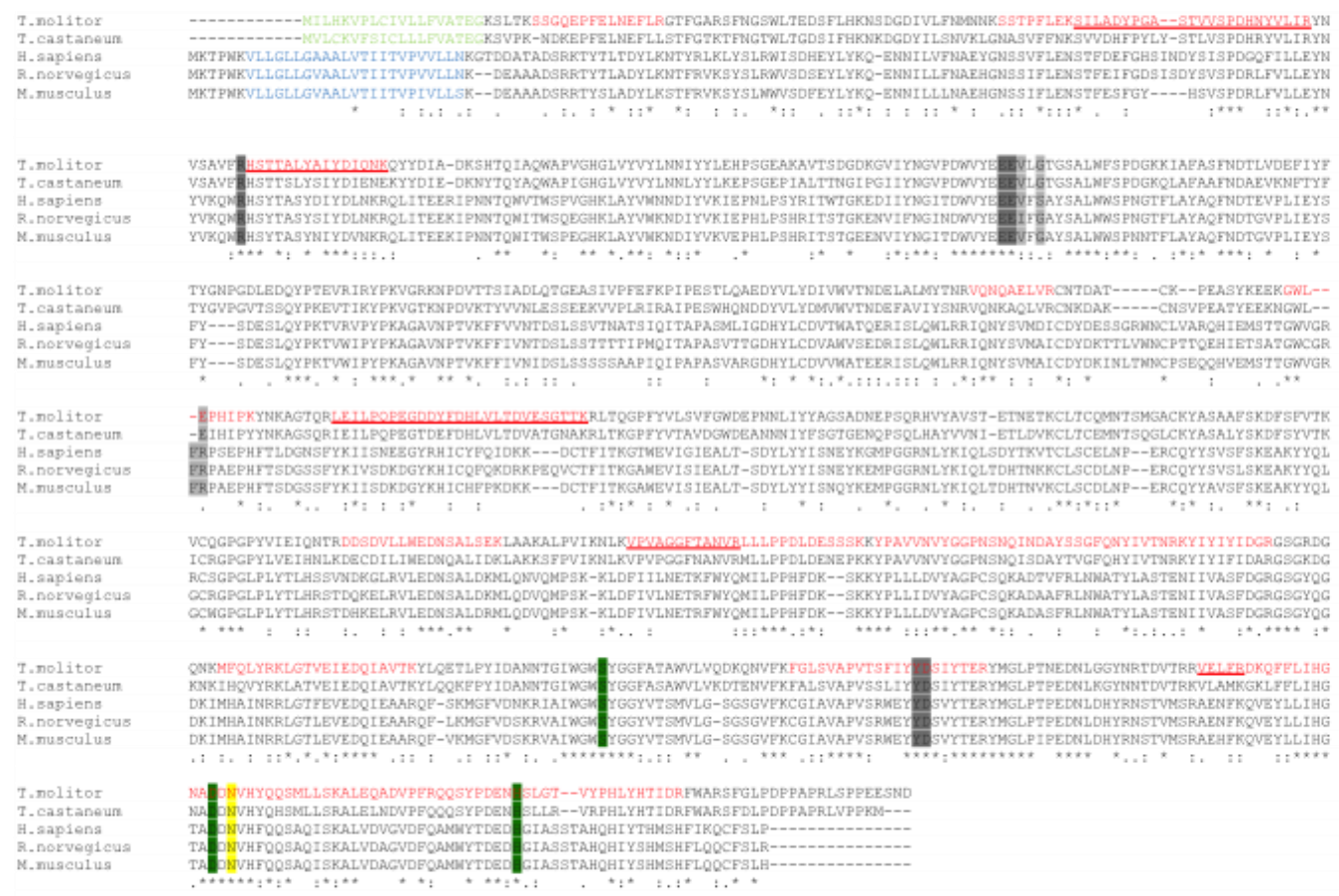


Figure 5

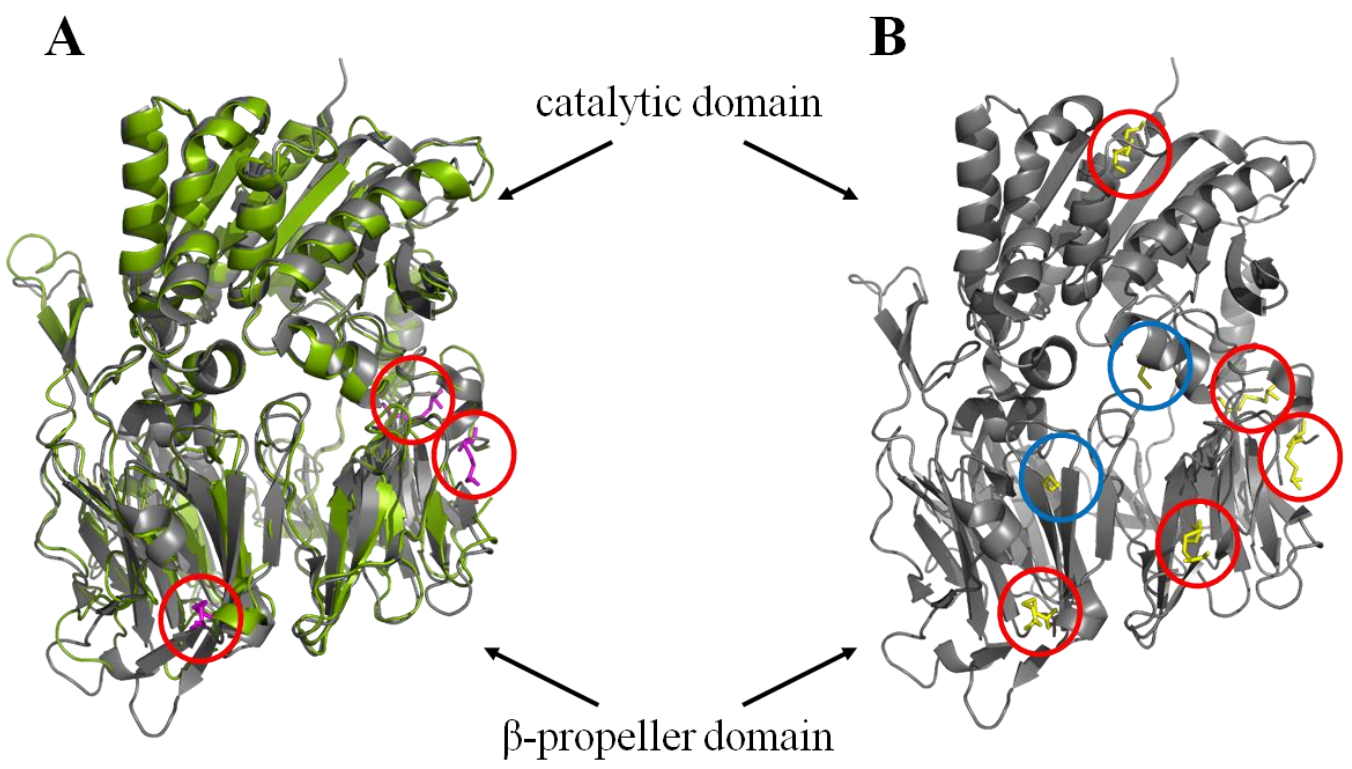


Figure 6

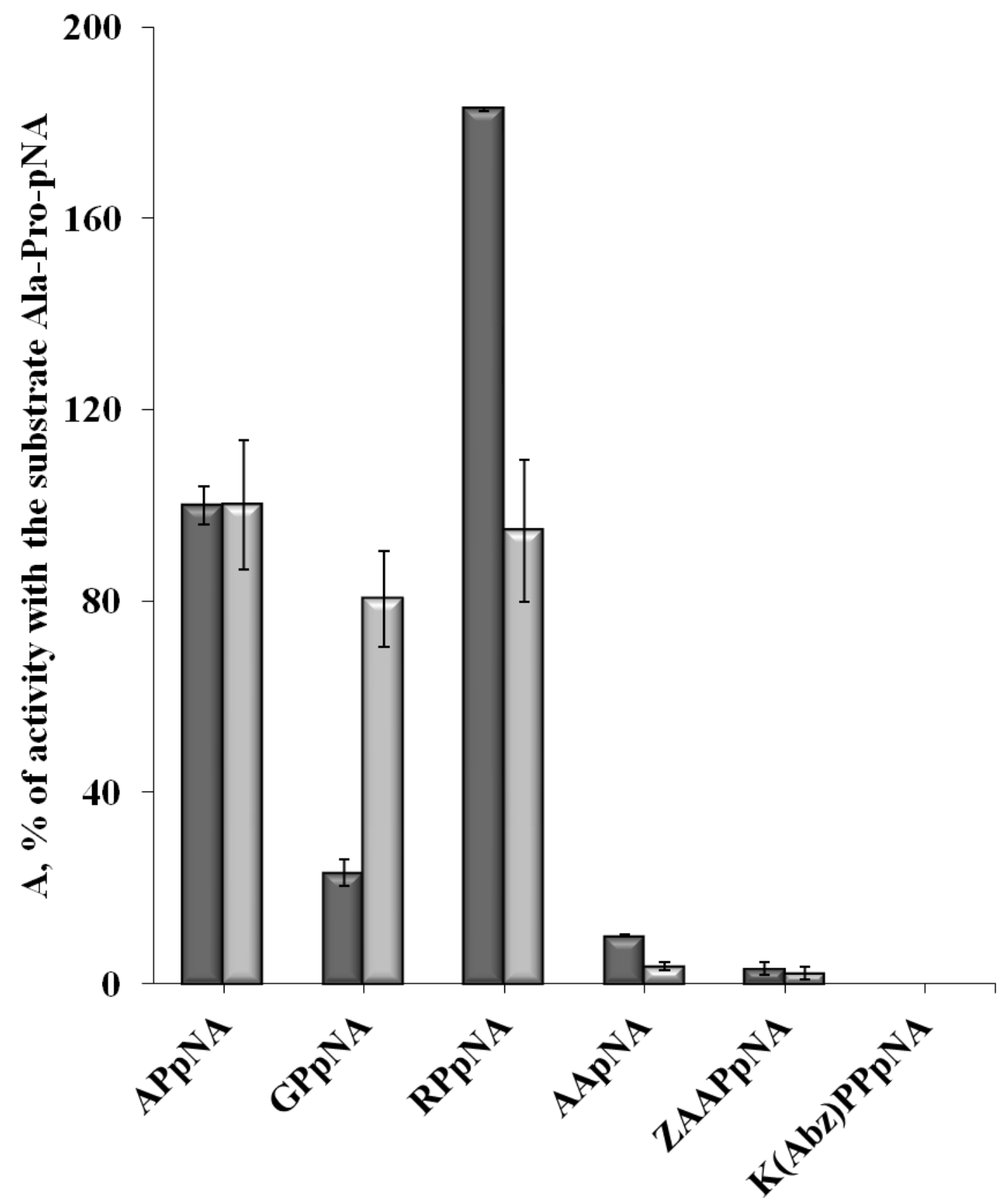


Figure 7

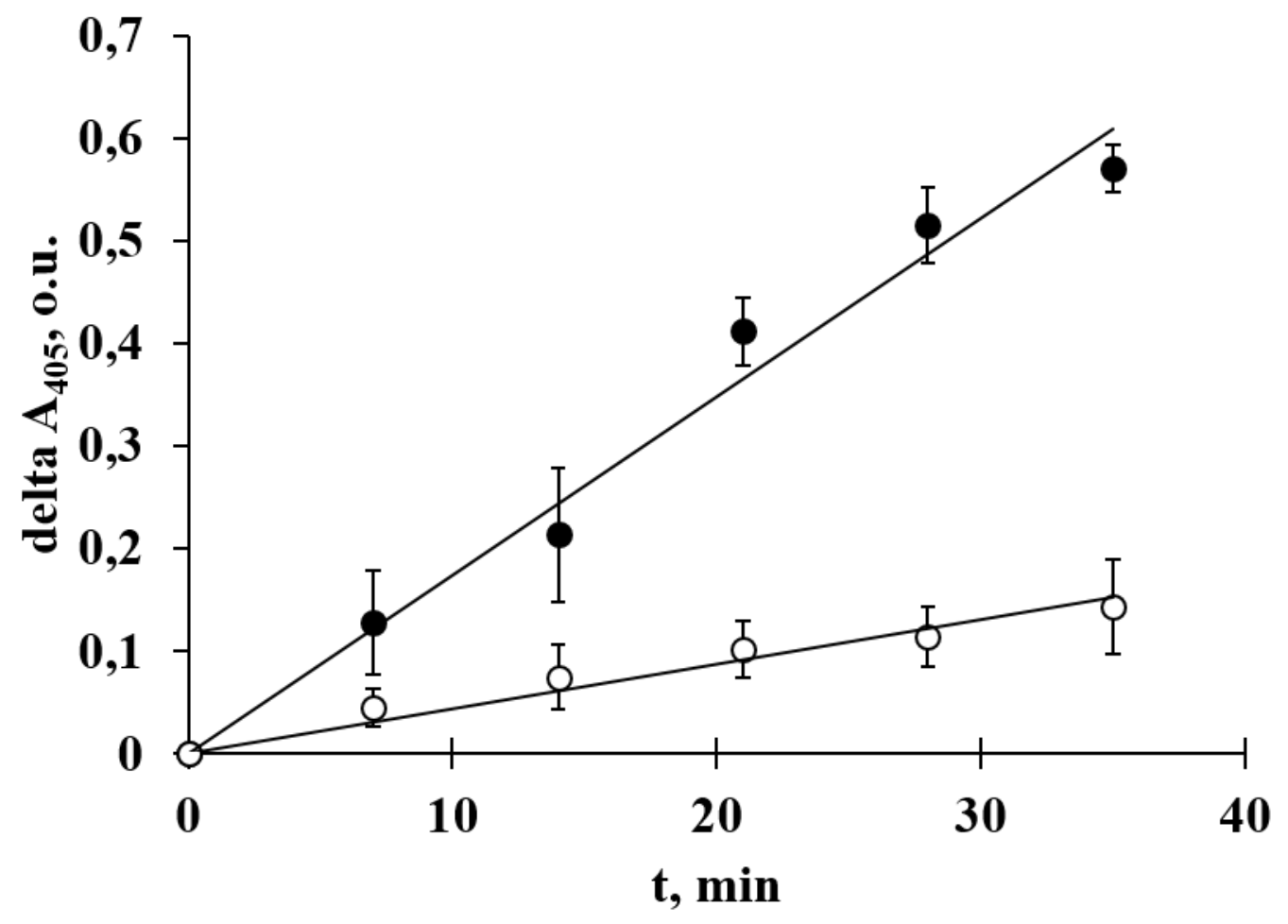


Table 1. Determination of the localization of DPP 4 in the T. molitor larval gut. The activity of DPP 4 was measured in the contents or tissues of the AM and PM by the hydrolysis of the substrate Ala-Pro-pNA (nmole/min/gut) in buffers of different $\mathrm{pH}$, as indicated ( $\mathrm{pH} 5.6$ buffer also contained $6.0 \mathrm{mM}$ cysteine).

\begin{tabular}{|l|c|c|c|}
\hline \multirow{2}{*}{\multicolumn{1}{|c|}{ Sample }} & \multicolumn{2}{c|}{ AM } & PM \\
\cline { 2 - 4 } & pH 5.6 & pH 7.9 & pH 7.9 \\
\hline Soluble contents & $2.08 \pm 0.10$ & $4.52 \pm 0.03$ & $3.10 \pm 0.09$ \\
\hline Insoluble contents & $0.14 \pm 0.06$ & $0.18 \pm 0.05$ & $0.52 \pm 0.20$ \\
\hline Tissues & $0.28 \pm 0.02$ & $0.85 \pm 0.09$ & $2.04 \pm 0.15$ \\
\hline
\end{tabular}


Table 2. Purification of TmDPP 4 from the AM of the T. molitor larval gut.

\begin{tabular}{|l|c|c|c|c|}
\hline \multicolumn{1}{|c|}{ Sample } & $\begin{array}{c}\text { Total Protein } \\
\text { (mg) }\end{array}$ & $\begin{array}{c}\text { Specific Activity } \\
\text { (OU/h*mg) }\end{array}$ & $\begin{array}{c}\text { Purification } \\
\text { Ratio }\end{array}$ & Yield (\%) \\
\hline Crude extract & 192 & 11.4 & 1 & 100 \\
\hline Sephadex G-150 & 17.0 & 85.2 & 7 & 66 \\
\hline Phenyl-sepharose & 0.53 & 1,480 & 130 & 36 \\
\hline MonoQ & 0.03 & 6,040 & 530 & 7 \\
\hline
\end{tabular}


Table 3. Effect of class-specific peptidase inhibitors and activators on TmDPP 4 activity.

\begin{tabular}{|c|c|c|}
\hline Inhibitor & $\begin{array}{c}\text { Inhibitor } \\
\text { concentration, M }\end{array}$ & $\begin{array}{l}\text { Residual } \\
\text { activity of } \\
\text { DPP } 4, \%\end{array}$ \\
\hline Control & 0 & 100 \\
\hline \multirow{3}{*}{ EDTA } & $10^{-2}$ & 102 \\
\hline & $10^{-3}$ & 104 \\
\hline & $10^{-4}$ & 107 \\
\hline \multirow{3}{*}{ DFP } & $10^{-2}$ & 4 \\
\hline & $10^{-3}$ & 25 \\
\hline & $10^{-4}$ & 77 \\
\hline \multirow{3}{*}{ PMSF } & $10^{-2}$ & 21 \\
\hline & $10^{-3}$ & 61 \\
\hline & $10^{-4}$ & 99 \\
\hline \multirow{3}{*}{ Pepstatin A } & $10^{-4}$ & 97 \\
\hline & $10^{-5}$ & 94 \\
\hline & $10^{-6}$ & 97 \\
\hline \multirow{3}{*}{ E-64 } & $10^{-4}$ & 92 \\
\hline & $10^{-5}$ & 101 \\
\hline & $10^{-6}$ & 104 \\
\hline \multirow{3}{*}{ Z-Pro-prolinal } & $10^{-3}$ & 60 \\
\hline & $10^{-4}$ & 88 \\
\hline & $10^{-5}$ & 95 \\
\hline \multirow{3}{*}{ Bestatin } & $10^{-3}$ & 99 \\
\hline & $10^{-4}$ & 96 \\
\hline & $10^{-5}$ & 97 \\
\hline \multirow{3}{*}{ Cys } & $6 \times 10^{-3}$ & 103 \\
\hline & $10^{-3}$ & 101 \\
\hline & $10^{-4}$ & 100 \\
\hline
\end{tabular}


Table 4. Effect of specific inhibitors on the activity of TmDPP 4 and $\operatorname{rhDPP} 4$.

\begin{tabular}{|c|c|c|}
\hline \multirow{2}{*}{ Inhibitors } & \multicolumn{2}{|c|}{$\mathrm{IC}_{50}, \mu \mathrm{M}$} \\
\cline { 2 - 3 } & TmDPP 4 & rhDPP 4 \\
\hline DFP & $0.37 \pm 0.01$ & $0.32 \pm 0.03$ \\
\hline Diprotin A & $390 \pm 50$ & $65 \pm 14$ \\
\hline Diprotin B & $2,500 \pm 500$ & $620 \pm 50$ \\
\hline Vildagliptin & $13 \pm 4$ & $1.9 \pm 1.4$ \\
\hline Sitagliptin & $17,500 \pm 500$ & $2.5 \pm 0.5$ \\
\hline
\end{tabular}




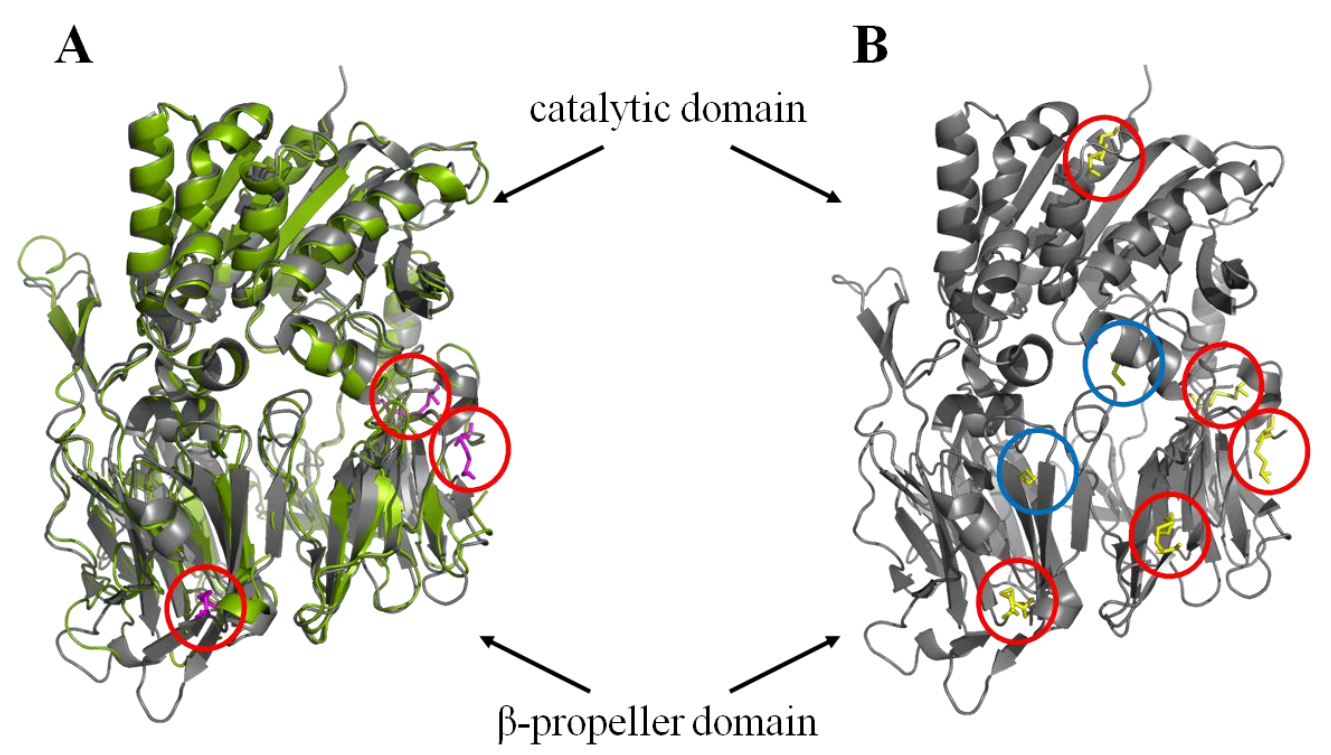

Predicted three-dimensional structure of Tenebrio molitor dipeptidyl peptidase 4 - an insect enzyme with digestive function 